\title{
Revisiting the age of the Florisbad hominin material
}

\section{THIS IS A PRESUBMISSION MANUSCRIPT}

\section{Lee R. Berger}

The Phillip Tobias Chair in Palaeoanthropology

Evolutionary Studies Institute

The University of the Witwatersrand

\&

Explorer at Large

The National Geographic Society

Lee.Berger@,Wits.ac.za

\section{John Hawks}

Vilas-Borghesi Distinguished Achievement Professor

Department of Anthropology

University of Wisconsin-Madison

\&

Visiting Professor

Evolutionary Studies Institute

University of the Witwatersrand

jhawks@,wisc.edu

\begin{abstract}
In 1996, Grün and coworkers provided an ESR age determination for a hominin molar from Florisbad, South Africa, at $259 \pm 35 \mathrm{ka}$. The most anatomically informative hominin specimen from Florisbad is a fragmentary craniofacial specimen, attributed by many to early Homo sapiens, which has been assumed to derive from the same individual as this tooth. Since 1996, evidence about the evolutionary context for the later Middle Pleistocene and its associated hominins in Africa had markedly changed. If the Florisbad date is accurate and if the molar is associated with the craniofacial specimen, this evidence may suggest that Homo naledi coexisted in time and geography with $H$. sapiens in southern Africa. Thus, the accuracy for all dates needs critical investigation. This study examines the published record of excavation and subsequent analyses for the Florisbad material. We find that the contemporary records raise doubt about the contemporaneity of the tooth and calvaria. The site's complex stratigraphy and the details about the tooth's discovery also pose challenges for the previous ESR age estimate. Because the fragmentary cranial specimen has value for morphological comparisons, developing additional means of understanding its geological age is necessary. The current data do not demonstrate the presence of $\mathrm{H}$. sapiens in southern Africa at $\sim 260 \mathrm{ka}$.
\end{abstract}


Very few chronometric ages have been reported for fossil hominins from the later Middle Pleistocene in Africa. This period is increasingly critical to understanding human evolution. It is a time when modern humans began to emerge as an identifiable lineage (Schlebusch et al. 2017; McDougall et al. 2005). Other hominin populations existed at this time, including the recently-discovered Homo naledi (Berger et al. 2015). Dirks et al. (2017) constrained the geological age for the Homo naledi assemblage from the Dinaledi Chamber, in the Rising Star cave system, at 236-335 ka. U-series dates from flowstone and direct ESR ages from hominin teeth provided the tightest minimum and maximum dates, within an overall chronology including consistent OSL on sediment, paleomagnetism from speleothems, and U-series ages from hominin enamel and dentin. The key dates were generated by two laboratories using a blinded sampling design. Establishing whether or not $H$. naledi and $H$. sapiens may have been in contact would clarify our understanding of the two species' ecology, evolution, and archaeological associations (Berger et al. 2017). But thus far few African sites preserving H. sapiens can be securely placed in time.

At present the most convincing evidence suggesting overlap in time between $H$. sapiens and $H$. naledi is the assemblage attributed to early $H$. sapiens from Jebel Irhoud, Morocco (Hublin et al. 2017). The Jebel Irhoud 3 fossil mandible was dated at $286 \pm 32$ ka by ESR, while stone tools from the same level were dated by thermoluminescence (TL) to $315 \pm 32 \mathrm{ka}$ (Richter et al. 2017). Morocco is at the opposite end of the continent, raising the question of whether $H$. sapiens may have been present more widely, including within southern Africa where it would overlap geographically with H. naledi.

The Florisbad hominin material, consisting of cranio-facial fragments and one tooth, were estimated to have an age of $259 \pm 35 \mathrm{ka}$. (Grün et al. 1996). The taxonomic assignment of the Florisbad specimen has varied over the years. Some authors have considered it to be a "late archaic human" (Grün et al. 1996). Hublin and coworkers (2017) attributed both Jebel Irhoud and Florisbad fossils to "early H. sapiens," and set them apart from "anatomically modern humans". In our view, these names are in need of better definition, but here we follow this usage to avoid confusion. Florisbad is only 400 $\mathrm{km}$ from Rising Star Cave. If H. sapiens did live at Florisbad at $260 \mathrm{ka}$, this would suggest the possibility that the two species were possibly sympatric, overlapping in both time and space. Therefore, we examined the record in detail to assess whether the date for the Florisbad calvaria is secure.

\section{The Relationship Between the Florisbad Cranial Material and the Tooth}

The ESR date of $259 \pm 35$ thousand years (Grün et al. 1996) was derived from a hominin upper third molar. Since the initial excavation of the site, most authors have assumed that this molar represents the same individual as the partial face and vault material from the site (Grün et al. 1996; Dreyer 1935; Drennan 1937; Clarke 1985), although several authors have been more conservative, either omitting any statement about the association of the material or noting the lack of clear association (Rightmire 2013; Brace et al. 1971). The preserved maxillary fragments do not preserve the portion that could confirm or reject a physical conjoin with the tooth (Figure 1). The tooth lacks diagnostic features 
that would allow reliable taxonomic attribution. It overlaps in morphology and metric dimensions with Early and Middle Pleistocene Homo species and also with recent modern human populations of southern Africa (Smith et al. 2015).
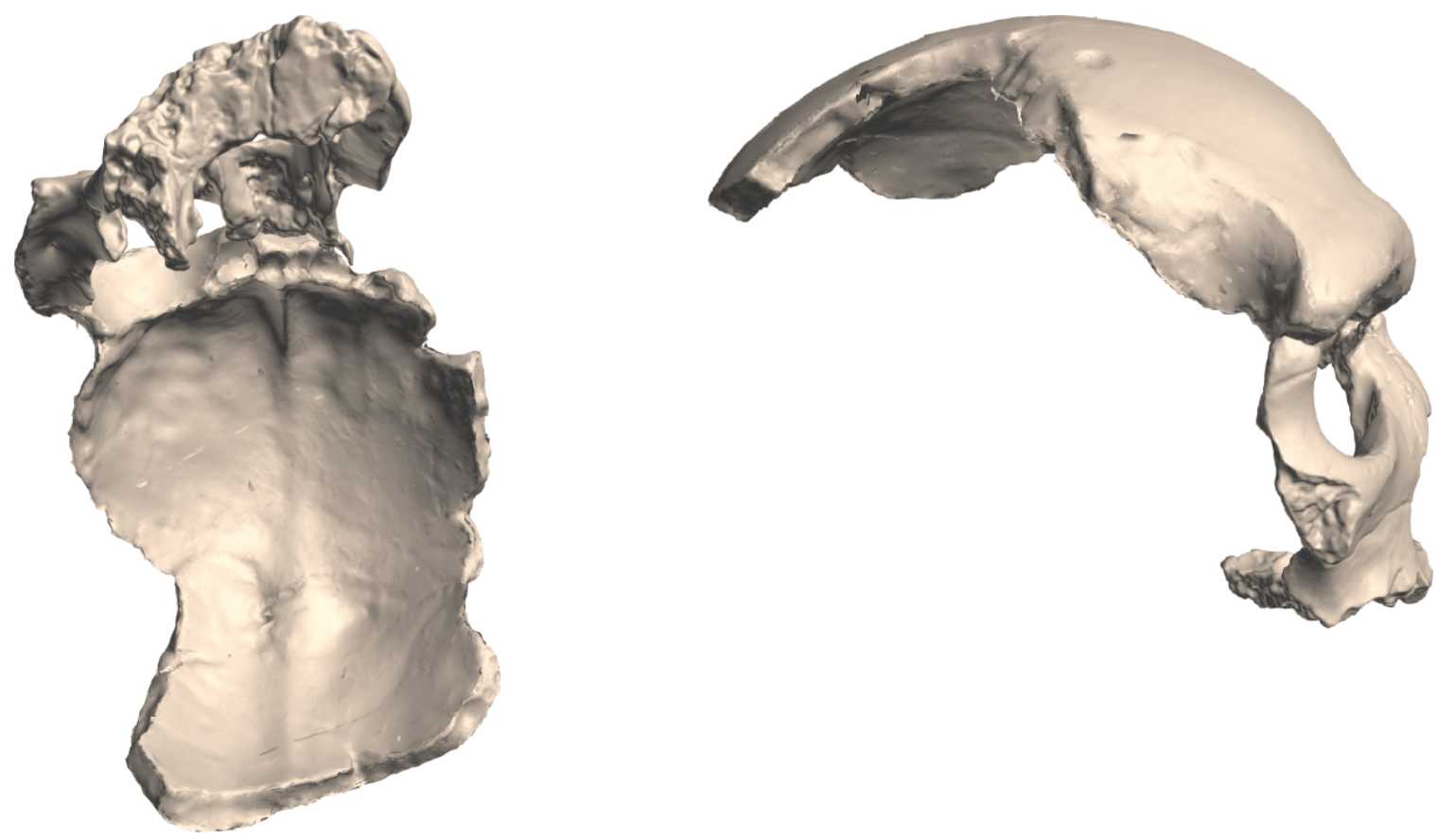

Figure 1: Surface reconstruction of the Florisbad craniofacial fragment in inferior (left) and right lateral (right) views. The incomplete maxilla does not preserve an alveolus (or alveoli) that would demonstrate a fit with the right $\mathrm{M}^{3}$. The cranial evidence does not exclude the tooth but is insufficient to demonstrate that the two represent a single individual.

Lacking the possibility of physical refitting, and without clear anatomical assignment, it is necessary to establish if the tooth and cranial material are associated by spatial position or other objective criteria. Dreyer (1935) stated that these remains were associated, but the documentation does not clearly demonstrate their spatial proximity. The criteria for accepting "association" were less stringent in the 1930s than now. For example, Dreyer (1935) and Drennan (1937) accepted a broad degree of association between archaeological material and the hominin cranial material that later workers ultimately rejected. Kuman and Clarke (1986:103) noted that "The complex spring stratigraphy, the pick and shovel excavation methods, and the total lack of good records on provenance for the early finds have created much confusion over the stratigraphic position of the Florisbad cranium and fauna."

The caution of later workers emerged as they recognized the complex nature of the Florisbad deposits. The spring water has high methane content from the underlying shale, and this methane has periodically led to gas explosions that disrupt and redeposit 
material. Parts of the stratigraphic profile are "explosion breccias" (Grobler 1988), and it was one of these explosions that first brought fossil material out of the site (Broom 1913). Desmond Clark (1955) examined the site while studying the MSA material, and wrote:

"Owing...to the disruptive action of the springs breaking through the deposits and thus making it possible for implements from the upper layers to find their way down into the lower levels the exact stratigraphical positions of specimens in these "eyes" must remain open to doubt. Clearly, therefore, only specimens found "in situ" in the undisturbed deposits away from the "eyes" [here, "eyes" refers to the "spring eyes" that were groundwater and methane sources] can be used to determine the true contents of the various layers."

Ronald Clarke (1985) considered the stratigraphic position of the Florisbad skull, which was found in a "debris cone" of one of the spring eyes. He described the eruption of material from the lowest level, Peat I, up through the overlying levels, and considered it "not impossible that the skull was originally in one of these higher levels and through spring disturbance was redeposited" (p. 304). Clarke did not consider this hypothesis likely owing to the differential preservation of bone in these levels. But if lithic artifacts can be reworked downward within the site, isolated teeth can also be reworked downward.

Some signs of probable reworking come from the ESR chronology itself. Grün et al. (1996) obtained ESR samples from both a test pit and from earlier collections from the spring. According to Grün et al. (1996), results showed a great scatter of ages through most of the site, excepting an MSA occupation horizon estimated to be $121 \pm 6 \mathrm{ka}$. These authors stated that the scatter of ESR results likely reflects the "reworking of material by spring action" (p. 500). We undertook further examination of these data to consider the extent of such reworking. Grün et al. (1996) presented data only in figures with no numerical tables. We used open source software (PlotDigitizer, http://plotdigitizer.sourceforge.net) to extract numerical data from figure 1a, and those are illustrated in our Figure 2. We note that data on sample depth in Figure 1a of Grün et al. (1996) appears to be opposite the expectation that age increases with depth: the youngest ESR ages come from samples reported at a depth of more than $600 \mathrm{~cm}$, while depths of less than $100 \mathrm{~cm}$ are associated with much higher ESR age estimates. This may indicate that Grün et al. (1996) mistakenly reported depth in inverse order, meaning that results lower in the graph actually came from samples at greater depth, not shallower depth as reported. In any event, it is clear that the ESR ages below the line marked as "MSA occupation horizon" are widely scattered, with ages immediately below this horizon nearly the same range as ages at the very bottom of the chart. The correlation of age and depth below the "MSA occupation horizon" level is small and nonsignificant $(r=$ $-0.13, p<0.56)$. Different samples taken at the same depth show very divergent ESR ages, suggesting either mixture across large intervals of depth (3 meters or more), or very different radiation doses for material at the same depth. These data derived from Figure 1a of Grün and collaborators (1996) reflect the situation within a test pit with documented stratigraphic depths for samples. The ESR ages from the original spring collections (ref. 1, figure 1b) cover an even broader range of time from $<100 \mathrm{ka}$ to $>350 \mathrm{ka}$ and include 
no information on spatial position or depth. The provenience of these samples is not secure.

[Figure 2]

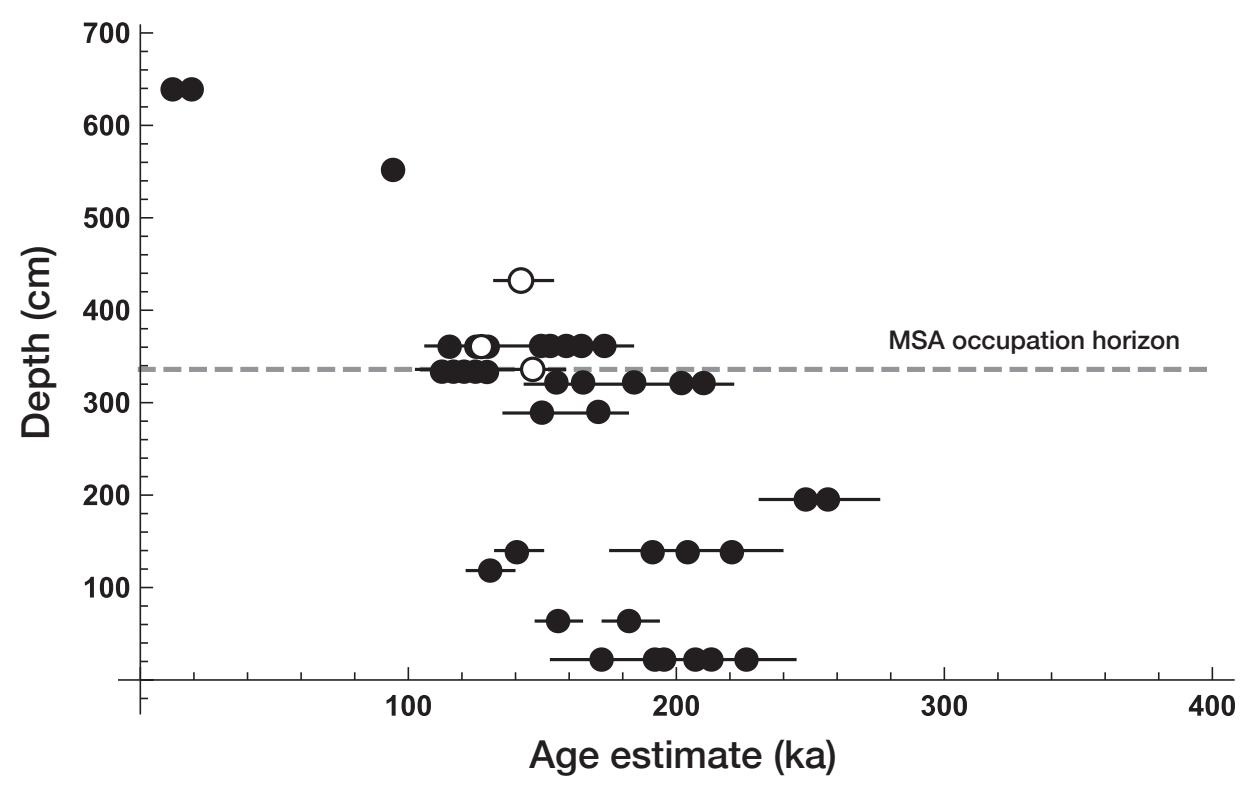

Figure 2. Results from Grün et al. (1), Figure 1a, reporting early uptake ESR ages (closed circles) and optically stimulated luminescence (OSL) ages (open circles) for samples from the third test pit. The depth of the MSA occupation horizon in this pit is indicated as in the original figure. The ESR data show no significant correlation of age and depth below this horizon.

In summary, the Florisbad spring deposits were substantially reworked and mixed, particularly in the spring eye areas likely due to methane explosions, including the area 
where the cranial material and tooth were found. ESR ages are consistent with substantial reworking where depth data have been recorded. The historical records and data do not prove that the molar and cranial material come from different individuals or times, but they do not provide sufficient evidence that they represent the same individual or time. These data do not substantiate the assumption that the tooth represents H. sapiens.

\section{Problems Estimating ESR Dose Rate}

Whether or not the Florisbad tooth can be associated with the cranial material, the ESR age of $259 \pm 35 \mathrm{ka}$ (Grün et al. 1996) does overlap with the range between the ante quem and post quem age constraints on the Dinaledi hominin deposit (Dirks et al. 2017). This overlap does not necessarily mean that the fossils from the two sites were synchronous. The large standard error on the Florisbad estimate renders it compatible with both much more recent and much more ancient ages, including ages more than 30 ka younger than the minimum age for the Dinaledi hominins at $226 \mathrm{ka}$, while the Dinaledi deposit could be as old as $335 \mathrm{ka}$. Nonetheless, the Florisbad date bears critical examination. The dating of the Jebel Irhoud 3 specimen (Richter et al. 2017) provides a comparable example. An initial U-series/ESR age of $160 \pm 16 \mathrm{ka}$ was reported in 2007 based upon an estimated dose rate from a sediment sample (Smith et al. 2007). Later this age was revised upward to $286 \pm 32 \mathrm{ka}$ based upon in situ dosimetry (Richter et al. 2017). In the case of Florisbad, the combined U-series/ESR method itself was not used to obtain the 1996 results (Grün et al. 1996), making the estimates of dose rate and uptake model especially critical.

Blackwell (2006) reviewed several factors that are problematic for ESR dating, including heat, pressure, the pattern of uranium uptake, changing cosmic dose rates, and altered sediment cover. For fossils like the Florisbad tooth that were excavated in the past without modern excavation recording, geochronologists may have little basis for assumptions about such factors. The heterogeneity of ESR ages at the same depths found by Grün et al. (1996) may reflect these factors in addition to reworking.

The site occurs within a warm spring, where temperature of the water presently has an average temperature of $29^{\circ} \mathrm{C}$ (Grün et al. 1996). The methane explosions that occurred periodically at the site, which disrupted the deposits, likely generated high temperatures at times (Grobler 1988). These explosions likely would also have exposed the fossils to periodic high-pressure shock waves, potentially up to 9 bars, in the spring eyes. Although no one has examined the effect on tooth enamel, experiments by Lee and Schwarcz (1993) suggested that pressures far in excess of 10 bars would be needed to affect the signals in quartz, which has less stable signals that those in enamel. Investigation of temperature and pressure effects within this context would be valuable.

The dose rate from cosmic radiation and uranium uptake is the most important source of uncertainty in the ESR ages. Calculating the tooth's radiation exposure correctly depends on understanding its depositional history. Due to the factors noted above, the exact depositional history of the tooth is uncertain, but Dreyer (1935) reported that the hominin material came from the level of Peat 1. According to Grün et al. (1996, p. 500): "For age 
calculation we used saturation water contents, a cosmic dose rate for a depth of $5 \pm 1 \mathrm{~m}$ and the average concentration of radioactive elements of white sand layers." The white sand layers at Florisbad are the shallowest deposits, far above the level of Peat 1 where the tooth is reported to have been found. Peat poses a significant issue for ESR dating, because the natural acids in peat including fulvic and humic acids tend to adsorb uranium, binding it to clay minerals (Szalay 1969; Van der Wijk et al. 1986; Zayre 2006; Field et al. 2018). The tendency for peat to concentrate uranium can be extreme, with enrichment of $10^{4}$ to $10^{6}$ times the uranium concentration in solution reported in some peatlands (Shotyk 1988). For example, Shotyk (1988) discusses a Canadian site where a basal peat uranium concentration of $1290 \mathrm{ppm}$ was immediately above sands with a concentration of less than $40 \mathrm{ppm}$, and springwater of $50 \mathrm{ppb}$ (Halbach et al. 1980). The concentration of radioactive elements measured in the white sand at Florisbad may be orders of magnitude different from the environment experienced by the fossils in the peats.

Springs like Florisbad can also operate as open systems for uranium, as upwelling water may fluctuate in uranium content, leading to leaching of uranium from enamel and bone. Leaching can occur in cave sites but is an even more common factor in open air sites. Grün (2009) investigated the performance of early, linear, or late uranium absorption models for ESR carried out at a large sample of sites, finding that the large majority of open-air sites do not conform to early or linear uptake models. Leaching of uranium is one of the major factors he identified.

One additional element of uncertainty is the possibility of past radiographic analysis of the specimen. Many hominin fossils recovered before 1980 were analyzed using X-rays. Records from this time, if they exist, generally lack details like the energies or exposure times used. Moreover before 1960, radiography used much higher dose rates and dose times, and often had been poorly calibrated (Paul 1958). More recently, CT scans also have been used to examine fossils. Both X-rays and CT scans can produce enough increases in the accumulated doses recorded by tooth enamel to be measurable. Thus, if the history of X-rays and CT scans is unknown, the higher accumulated dose would inadvertently increase the calculated ESR age for the fossil (Grün et al. 2012).

\section{Conclusions}

Florisbad spring deposits experienced complex depositional processes. The records of excavation of the hominin cranial material and tooth do not demonstrate that these represent the same individual to the degree that can satisfy today's standards of association. The site has a complex geology, with heat, pressure, and intermittent explosive disruptions, and reworking of sediments. This reworking may explain the disparate ESR results from the 1996 study (Grün et al. 1996). Alternatively, the ESR variability may relate to variation in radiation dose in the site. The model used to determine ESR age in the initial work used a dose rate assumed from the white sands, while the hominin tooth and deeper material (with high and variable ESR ages) come from peat deposits. Peat is a uranium concentrator, likely resulting in a different radiation environment than the overlying white sands. The possible importance of fluctuating 
springwater uranium content and leaching, important at other open-air sites, should also be considered.

It is premature to conclude, based on the 1996 ESR age of the Florisbad tooth, that $H$. sapiens occurred in this part of Africa at $259 \pm 35 \mathrm{ka}$. We suggest that future consideration of the date of the Florisbad " $H$. sapiens" cranial material revisit with a multidisciplinary approach recognizing the uncertainty of association, taxonomic attribution, and the complexity of the spring site. 


\section{References cited:}

Berger LR, Hawks J, Dirks PH, Elliott M, Roberts EM. Homo naledi and Pleistocene hominin evolution in subequatorial Africa. eLife. 2017;6:e24234.

https://doi.org/10.7554/eLife.24234.001

Blackwell BA. Electron spin resonance (ESR) dating in karst environments. Acta Carsologica. 2006;35:123-153. https://doi.org/10.3986/ac.v35i2-3.236

Brace CL, Nelson H, Korn N. Atlas of Fossil Man. New York: Holt, Rinehart and Winston 1971.

Broom R. Man contemporaneous with extinct animals in South Africa. Annals of the South African Museum. 1913;12:13-16.

Clark JD. A note on a wooden implement from the level of Peat I at Florisbad, Orange Free State. Navorsinge van die Nasionale Museum: Researches of the National Museum. 1955;1:135-140.

Clarke RJ. A new reconstruction of the Florisbad cranium, with notes on the site. In: Ancestors: The Hard Evidence, Delson E ed. New York: Alan R. Liss 1985:301-305.

Dirks PH, Roberts EM, Hilbert-Wolf H, Kramers JD, Hawks J, Dosseto A, Duval M, Elliott M, Evans M, Grün R, Hellstrom J. The age of Homo naledi and associated sediments in the Rising Star Cave, South Africa. eLife. 2017;6:e24231. https://doi.org/10.7554/eLife.24231.001

Drennan MR. The Florisbad skull and brain cast. Transactions of the Royal Society of South Africa. 1937;25:103-14. https://doi.org/10.1080/00359193709519748

Dreyer TF. A human skull from Florisbad, Orange Free State, with a note on the endocranial cast, by CU Ariens Kappers. Proc Koninklijke Akad Wetenschappen te Amsterdam. 1935;38:3-12.

Field E, Marx S, Haig J, May JH, Jacobsen G, Zawadzki A, Child D, Heijnis H, Hotchkis $\mathrm{M}$, McGowan $\mathrm{H}$, Moss P. Untangling geochronological complexity in organic spring deposits using multiple dating methods. Quaternary Geochronology. 2018;43:50-71. https://doi.org/10.1016/j.quageo.2017.10.002

Grobler JC. The Florisbad mineral spring: its characteristics and genesis: conclusions. Navorsinge van die Nasionale Museum: Researches of the National Museum. 1988;5:477-483.

Grün R, Athreya S, Raj R, Patnaik R. ESR response in tooth enamel to high-resolution CT scanning. Archaeological and Anthropological Sciences. 2012 Mar 1;4(1):25-8. 
Grün R, Brink JS, Spooner NA, Taylor L, Stringer CB, Franciscus RG, Murray AS.

Direct dating of Florisbad hominid. Nature. 1996;382:500-501.

https://doi.org/10.1038/382500a0

Grün R. The relevance of parametric U-uptake models in ESR age calculations.

Radiation Measurements. 2009;44:472-476.

https://doi.org/10.1016/j.radmeas.2009.02.011

Halbach P, Von Borstel D, Gundermann KD. The uptake of uranium by organic substances in a peat bog environment on a granitic bedrock. Chemical Geology. 1980;29:117-38. https://doi.org/10.1016/0009-2541(80)90009-1

Hublin JJ, Ben-Ncer A, Bailey SE, Freidline SE, Neubauer S, Skinner MM, Bergmann I, Le Cabec A, Benazzi S, Harvati K, Gunz P. New fossils from Jebel Irhoud, Morocco and the pan-African origin of Homo sapiens. Nature. 2017;546:289-292.

https://doi.org/10.1038/nature22336

Kuman K, Clarke RJ. Florisbad — new investigations at a Middle Stone Age hominid site in South Africa. Geoarchaeology. 1986;1:103-25.

https://doi.org/10.1002/gea.3340010201

Lee HK, Schwarcz EP. An experimental study of shear-induced zeroing of ESR signals in quartz. Applied Radiation and Isotopes. 1993;44:191-195.

https://doi.org/10.1016/0969-8043(93)90218-Y

Paul IR. Is our x-ray machine a hazard?. Oral Surgery, Oral Medicine, Oral Pathology. 1958 Mar 1;11(3):282-8.

Richter D, Grün R, Joannes-Boyau R, Steele TE, Amani F, Rué M, Fernandes P, Raynal JP, Geraads D, Ben-Ncer A, Hublin JJ. The age of the hominin fossils from Jebel Irhoud, Morocco, and the origins of the Middle Stone Age. Nature. 2017;546:293-296.

https://doi.org/10.1038/nature22335

Rightmire GP. Later Middle Pleistocene Homo. In: Handbook of Paleoanthropology, Tattersall I, Henke W, eds. Berlin: Springer-Verlag 2013:1-20.

https://doi.org/10.1007/978-3-642-27800-6 55-5

Shotyk W. Review of the inorganic geochemistry of peats and peatland waters. EarthScience Reviews. 1988;25:95-176. https://doi.org/10.1016/0012-8252(88)90067-0

Smith P, Brink JS, Hoffman JW, Bam LC, Nshimirimana R, De Beer FC. The late Middle Pleistocene upper third molar from Florisbad: metrics and morphology.

Transactions of the Royal Society of South Africa. 2015;70:233-244.

https://doi.org/10.1080/0035919X.2015.1065930

Smith TM, Tafforeau P, Reid DJ, Grün R, Eggins S, Boutakiout M, Hublin JJ. Earliest evidence of modern human life history in North African early Homo sapiens. 
Proceedings of the National Academy of Sciences, U.S.A. 2007;104:6128-33. https://doi.org/10.1073/pnas.0700747104

Szalay A. Accumulation of uranium and other micrometals in coal and organic shales and the role of humic acids in these geochemical enrichments. Arkiv för Mineralogi Och Geologi 1969; 5:23-35.

Van Der Wijk A, El-Daoushy F, Arends AR, Mook WG. Dating peat with U/Th disequilibrium: some geochemical considerations. Chemical Geology: Isotope Geoscience section. 1986;59:283-292. https://doi.org/10.1016/0168-9622(86)90077-1

Zayre I, Gonzalez A, Krachler M, Cheburkin AY, Shotyk W. 2006. Spatial distribution of natural enrichments of aresenic, selenium, and uranium in a minerotrophic peatland, Gola di Lago, Canton Tichino, Switzerland. Environmental Science and Technology 2006;40:6568-6574. https://doi.org/10.1021/es061080v 